\title{
Development of a Modified Version of the Spinal Function Sort (M-SFS): A Mixed Method Approach
}

\author{
Svenja Janssen ${ }^{1}$ - Maurizio A. Trippolini ${ }^{1} \cdot \operatorname{Roger}$ Hilfiker $^{2} \cdot$ Peter Oesch $^{3}$
}

Published online: 23 October 2015

(c) The Author(s) 2015. This article is published with open access at Springerlink.com

\begin{abstract}
Purpose To develop a modified version of the spinal function sort (M-SFS) by measuring work-related self-efficacy beliefs in patients with chronic low back pain. Methods A mixed method design consisting of three different methods (M1-3) was performed. In semi-structured interviews participants were asked how often they performed the activities of the 50 SFS items in 1 week, and which spinal postures and movements were associated with their back pain (M1). Quantitative analysis of previously obtained SFS data investigated internal consistency, unidimensionality, item response, and floor and ceiling effect (M2). Experts rated the SFS items based on their relevance (M3). The findings from these methods were used within a final scoring system for item reduction. Results From semistructured interviews with 17 participants, eight new items emerged (M1). Quantitative analysis of 565 data sets (M2) revealed very high internal consistency of all items (Cronbach's alpha $=0.98$ ) indicating item redundancy; unidimensionality of the SFS was supported by principal component analysis; good item response was confirmed by Rasch analysis; and a floor effect of four items depicting very heavy material handling was found. Experts agreed on 8 out of the 50 SFS as relevant (M3). From the original SFS, 12 items met the predefined summary score of 9 .
\end{abstract}

Svenja Janssen

svenja.janssen@rehabellikon.ch

1 Department of Work Rehabilitation, Rehaklinik Bellikon, Suva Care, 5454 Bellikon, Switzerland

2 School of Health Sciences, HES-SO Valais-Wallis, University of Applied Sciences and Arts Western Switzerland Valais, Sion, Switzerland

3 Department of Research, Rehabilitation Centre Valens, Valens, Switzerland
Conclusions A modified version of the SFS with 20 items has been developed. Feasibility, reliability and validity of this modified version must be tested before it can be used in clinical practice.

Keywords Back pain · Self-efficacy beliefs · Questionnaire · Work

\section{Introduction}

Low back pain (LBP) and its consequences for society remains a global health problem [1-3]. However, less than $15 \%$ of LBP can be explained by specific back diseases such as vertebral fracture, tumor, infection, inflammatory diseases, nerve root compression, spondylolisthesis, spinal stenosis and definite instability [4]. Nonspecific LBP (NSLBP) is not attributed to the above-mentioned specific causes and about $10 \%$ of these patients develop chronic NSLBP [4].

The primary treatment goal in patients with chronic NSLBP is a return to work (RTW). The assessment of risk factors for non-return to work (N-RTW) plays an important role in their management [5]. Perceived self-efficacy is a relevant psychosocial factor contributing to the outcome in patients with chronic musculoskeletal pain [6]. According to Bandura, perceived self-efficacy affects how people behave in difficult situations, and people who doubt their capabilities shy away from tasks which they view as personal threats $[7,8]$. Within the bio-psychosocial model of health it is suggested that work-related self-efficacy beliefs are more closely related to work disability than actual physical ability [9-12]. Consequently, it is recommended that the self-efficacy beliefs of patients with chronic NSLBP are measured, for example, by questionnaire [3]. 
Although questionnaires usually have many advantages, such as being cheap, easy to administer and to interpret, they also have limitations. The use of questionnaires depends on literacy and linguistic skills. These skills may be limited in patients with different mother tongues, resulting in lower response to questionnaires [13]. A way to overcome these limitations is through the use of picturebased questionnaires [14]. One questionnaire for the measurement of work-related self-efficacy beliefs is the spinal function sort (SFS) [15]. The SFS consists of 50 depicted items that are linked to demonstrable, specific work-related tasks that involve the spine. The respondent to the SFS is asked to rate the 50 various activities involving the spine on a 5-point scale from 1 ("able") through 2, 3, and 4 ("restricted") to 5 ("unable") or, as a sixth possibility, to tick the question mark ["?" (don't know)] if he or she is not sure of being able to perform the activity. A maximal point score of 200 can be reached. The SFS has been translated and validated in different languages and is used in several countries [16-19]. It is used in work rehabilitation programs in conjunction with functional capacity evaluation (FCE) to compare work-related self-efficacy beliefs with observed functional capacity [19-21].

Several studies have investigated the measurement properties of the SFS [16-18, 22] revealing adequate reliability, construct, and predictive validity for RTW at 1-year follow up for patients with long-term work disability due to chronic NSLPB [17]. Furthermore, high internal consistency, Cronbach's alpha $>0.95$, indicating item redundancy, is reported [17, 18, 22]. In addition, four items showed floor effects with $>85 \%$ of the participants, who perceived themselves as unable to perform the displayed activity $[17,18]$. Two studies concluded that the SFS could be improved by item reduction as well as by updating some of the old-fashioned pictures [17, 18]. Furthermore, the current version of the SFS does not include items that describe prolonged work postures, such as sitting or standing [23], which are reported as risk factors for LBP $[24,25]$. Based on these findings, the purpose of this study was to develop a modified version of the SFS (M-SFS) for patients with chronic NSLBP.

\section{Methods and Material}

\section{Study Design}

A mixed methods design was used in this study to modify the SFS [26, 27]. Mixed methods studies combine quantitative and qualitative methods to allow for a better understanding of the research problem instead of using one method alone [26]. The following three methods (M) were applied (see also Fig. 1):
M1: Interviews with subjects with CLBP

M2: Quantitative analysis of the SFS items based on data from previous studies [17, 21, 28]

M3: Experts' opinions.

\section{M1: Interviews}

\section{Participants}

Subjects were recruited from the personnel (health care professionals, technicians, office workers, etc.) of the rehabilitation center at Bellikon, Switzerland. Inclusion criteria were: nonspecific CLBP for more than 3 months, aged between 18 and 65 years, no other severe disease or permanent injuries of the spinal cord, sufficient German language ability to be able to answer questions in the interviews, and a completed written informed consent form. Pregnancy was an exclusion criterion for female participants.

Ethics approval for this mixed methods study design was granted from the Medical Ethics Committee of the Canton Aargau, Switzerland (EK: 2012/073). All participants signed a written informed consent form.

\section{Frequency Analysis}

The interview consisted of three parts. Participants first completed the SFS plus an adapted version of the SFS asking for the perceived weekly frequency ("often," "sometimes," "seldom," "never") of each task depicted in the SFS. Completion of the questionnaires took 15-20 min in total. The perceived frequency of these tasks was viewed as an indication from the patient's perspective, of the relevance of these items in everyday life.

\section{First Qualitative Analysis}

Semi-structured interviews with the participants were then conducted asking which spinal postures and movements (that are not included in the SFS) they believed to be associated with their back pain. The results of the interviews should help to integrate the patients' perspective on postures and activities and their association with back pain into the modified version of the SFS. Participants were asked two phenomenological research questions which were used to lead the qualitative analysis process for exploring the themes of the new postural tolerance items [29]. The two research questions were: "During which activities do you feel restricted because of your back pain? Are they mentioned in the questionnaire?" (German: Gibt es Tätigkeiten, die Ihnen Schwierigkeiten aufgrund Ihrer Rückenbeschwerden bereiten? Welche sind das und sind 
Fig. 1 Study design

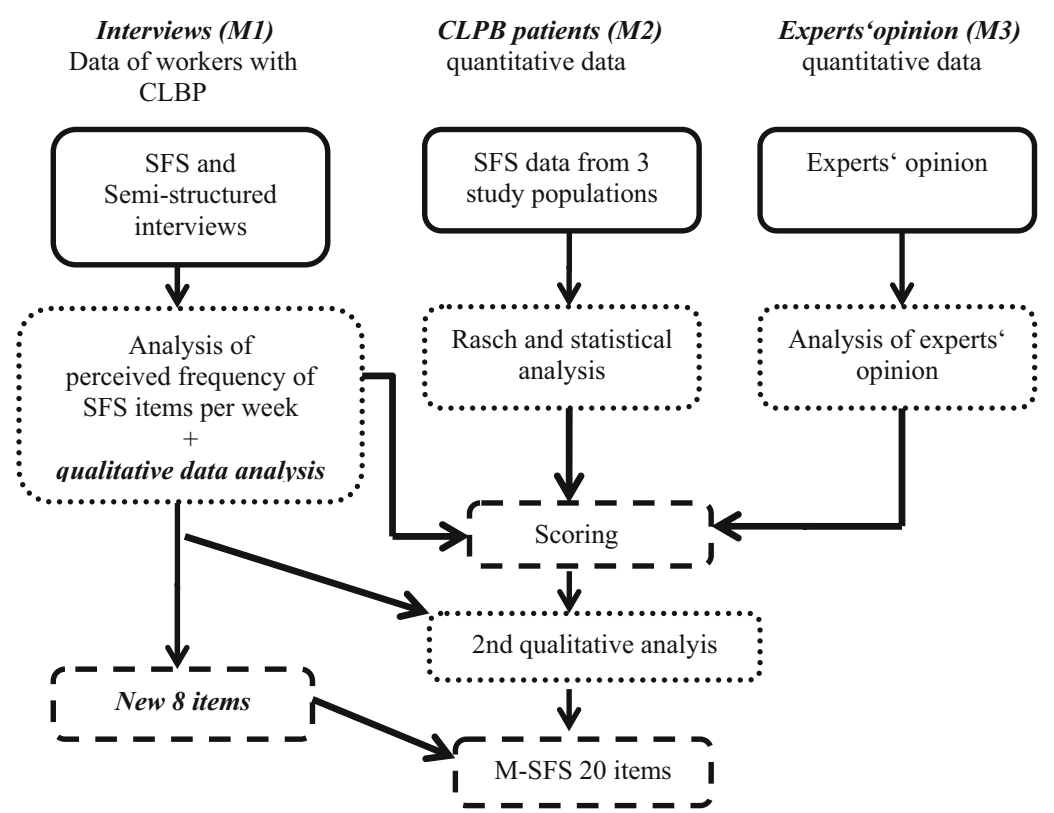

$$
\begin{aligned}
& \text { Abbreviations: } \\
& \text { M1= Method 1 } \\
& \text { M2= Method } 2 \\
& \text { M3 = Method } 3 \\
& \text { CLBP= Chronic low back pain } \\
& \text { SFS = Spinal Function Sort } \\
& \text { M-SFS= Modified Spinal Function Sort }
\end{aligned}
$$

diese im Fragebogen benannt?), and "Which prolonged postures cause pain in your back?" (German: Welche Positionen die Sie über längere Zeit einnehmen lösen Schmerzen in Ihrem Rücken aus?).

\section{Second Qualitative Analysis}

Finally, participants were asked which SFS items they experienced as redundant. Those items were excluded from the final M-SFS.

\section{Interview Process}

Participants had the opportunity to speak out loud throughout the whole of the interview process. This method of the three-part test is recommended for the qualitative examination of questionnaires [30]. The duration of the interview was 40-50 min per participant, including filling out the questionnaires.

The interviews were conducted by the first author. All interviews were audio-recorded and transcribed verbatim by a secretary who was not involved in the analysis process. The transcribed interviews were analyzed using the software ATLAS.ti for qualitative data analysis and themes were evaluated with the method of meaning units [31]. The sample was considered as saturated when no new themes emerged from the interviews [29, 32].

\section{Measures of Validity}

The interviewer has been working for 4 years as a physiotherapist in work-related rehabilitation and has regularly treated patients with chronic NSLBP for 6 years. The research and survey questions were discussed and selected by the study team before the interviews began and three pilot interviews were conducted. After the pilot interviews the formulation of phrases was adapted.

After every interview, an interview report was drawn up by the interviewer. As a quality check, two of the interviews were additionally transcribed by the interviewer and the texts compared with the secretary's transcription. The analysis of the interview data was verified by the second author (also a physiotherapist), who did not take part in the interviews. Disagreement on the analysis and results was discussed.

To avoid the risk of observer bias by the interviewer, two randomly selected interviews were video-recorded. Two experienced psychologists independently checked both videos. This provided the opportunity to analyze the data from a different perspective and to check for 
suggestive questions. The psychologists found no signs of suggestive questioning.

\section{M2: Quantitative Analysis of Previous SFS Data}

\section{Participants}

For the quantitative analysis, data were used from three previously published studies, one RCT and cross sectional studies [17, 21, 28]. Patients were participating in a function-oriented work rehabilitation program. Patients from two studies, who were referred to the Valens rehabilitation center, were aged between 20 and 55 years, suffered from chronic NSLBP (mean duration 1154 days), had no acute secondary diseases (e.g., vertebral fracture, tumor, infection, inflammatory diseases, nerve root compression and others), and had been on sick leave for a minimum of 6 weeks during the previous 6 months $[17,21]$. The third study included patients who were referred to the rehabilitation center at Bellikon, who were no older than 60 years, and had suffered from persistent pain after a traumatic accident (referred to rehabilitation more than 9 months (median) after the accident) without acute secondary diseases or permanent injuries [28]. All patients gave written informed consent as requested by the local Medical Ethics Committee.

\section{Statistical Analysis}

Unless reported otherwise, all statistical analyses were performed with SPSS (Statistical Package for Social Sciences, Version 21, IBM Corp.).

\section{Internal Consistency}

Internal consistency was calculated by item-to-total correlations and Cronbach's alpha. Analysis was also performed with half of the items, forming two groups (one with the even numbered items and one with the odd numbered items). Optimal consistency for measurements at group level was considered when alpha value was between 0.7 and 0.9 . Values $<0.7$ may be indicative for items measuring different traits, values $>0.9$ may be indicative for item redundancy [33].

\section{Unidimensionality}

Unidimensionality of the 50 SFS items was evaluated using principal component analysis (PCA) with Kaiser normalization and varimax rotation using the software $R$ [34]. An eigenvalue criterion of 1.0 was used for the factor analysis.
Item Response

The fit of the items to the Rasch model was examined with mean square infit and outfit statistics from Rasch analysis [35]. We interpreted values between 0.5 and $<1.5$ as a good fit, low but still sufficient if the item fit was between 1.5 and 2 , and insufficient fit was defined as values above 2 or below 0.5 [36].

\section{Floor and Ceiling Effect}

Floor or ceiling effect was set if an item was scored $>85 \%$ at the lowest or highest score of the 6-point scale of the SFS [37].

\section{M3: Experts' Opinions}

Four experts (the authors), with more than 5 years' experience as physiotherapists in work-related rehabilitation settings, were requested to independently score which of the 50 SFS items were important in relation to patients with chronic NSLBP. Every expert rated the relevance of every SFS item with "yes" or "no" (y/n). All four ratings were matched together and points were given for each item within the scoring.

\section{Final Item Selection for the M-SFS}

Final item selection was performed by applying the adapted Stanton criteria for length reduction of self-reporting scales [38]. For item selection, a summary scoring was developed for each SFS item based on the results of methods 1-3. The summary score consisted of the following criteria: perceived frequency of each item during a common week, item-to-total correlation, principal component analysis, Rasch analysis, floor and ceiling effect and experts' opinions on the relevance of the items (see Table 1). Items below the total summary score of 9 , from a maximal 12 points, were not selected for the SFS shortened questionnaire. The selected items from the summary scoring and the new themes mentioned in the interviews, created the new questionnaire.

\section{Results}

\section{M1: Interviews}

\section{Participants}

Seventeen workers with chronic NSLBP from several professions at the rehabilitation center in Bellikon (Aargau), Switzerland, participated in the interviews. Eight men 
Table 1 Scoring for final item selection

\begin{tabular}{lll}
\hline Category & Cut-off & Scores \\
\hline $\begin{array}{l}\text { Perceived weekly } \\
\text { frequency of activities }\end{array}$ & $>13$ times & 2 \\
("often" and & $<6$ times & 1 \\
"sometimes") & $0.6-0.9$ & 0 \\
Item-to-total correlation & $0.4-0.59$ & 2 \\
& $<0.4$ or $>0.9$ & 1 \\
Principal component & Loading on one factor $>0.5$ & 2 \\
analysis & Loading on two or no factor & 0 \\
& $>0.5$ & \\
Rasch analysis (item fit) & $0.5-1.5$ & 2 \\
& $>1.5$ to 2 & 1 \\
& $>2$ or $<0.5$ & 0 \\
Floor or ceiling effect & $<85 \%$ & 2 \\
& $>85 \%$ & 0 \\
Experts' opinion on & All experts & 1 \\
relevance of SFS item & 3 out of 4 & 0.75 \\
"“yes") & 2 out of 4 & 0.5 \\
& 1 out of 4 & 0.25 \\
& None & 0 \\
\hline
\end{tabular}

SFS spinal function sort

and nine women with a mean age of 44 years were interviewed. Reported current pain was mentioned with 1.6 in mean, and standard deviation (SD) of 1.4 on a numeric rating scale (NRS 0-10). The average duration of pain in days was 3796. Of the sample, $35 \%$ had more than 9 years of school education and were married. Single marital status was reported by $47 \%$. German was spoken by 82 , and $88 \%$ were in possession of a work contract with a position as worker or office worker in $65 \%$ of all mentioned work roles (see Table 2).

\section{Frequency Analysis}

The analysis of the frequency of performance of the SFS items per week showed that the following six items were rated as activities performed on a daily basis (i.e., often): bending (items 1 and 2), lifting 10 kilos (item 15), forward standing for more than 5 min (item 19), and trunk rotation (items 30 and 32). Fifteen items were assessed as tasks that were performed three to four times each week (i.e., sometimes).

\section{First Qualitative Analysis}

In total, there were 20 subjects available for data collection but three subjects were excluded from the study: two subjects did not agree to be audio-recorded and one subject had filled out the SFS on many previous occasions. In the latter case, this subject was not interviewed to avoid the
Table 2 Demographics of the interviewed participants with chronic $\operatorname{NSLBP}(\mathrm{n}=17)$

\begin{tabular}{|c|c|c|c|c|}
\hline Variable & $\mathrm{n}$ & Mean & SD & $\%$ \\
\hline Age & 17 & 44 & 12 & \\
\hline Self-reported pain (NRS) & 17 & 2 & 1 & \\
\hline Duration of pain (days) & 17 & 3796 & 4554 & \\
\hline \multicolumn{5}{|l|}{ Gender } \\
\hline Male & 8 & & & 47 \\
\hline Female & 9 & & & 53 \\
\hline \multicolumn{5}{|l|}{ Education (years at school) } \\
\hline 6 years & 1 & & & 6 \\
\hline $7-9$ years & 10 & & & 59 \\
\hline$>9$ years & 6 & & & 35 \\
\hline \multicolumn{5}{|l|}{ Marital status } \\
\hline Single & 8 & & & 47 \\
\hline Married & 6 & & & 35 \\
\hline Divorced/parted & 2 & & & 12 \\
\hline Unknown & 1 & & & 6 \\
\hline \multicolumn{5}{|l|}{ Native language } \\
\hline German & 14 & & & 82 \\
\hline Italian & 1 & & & 6 \\
\hline Spanish & 1 & & & 6 \\
\hline Turkish & 1 & & & 6 \\
\hline \multicolumn{5}{|l|}{ Work-contract } \\
\hline Yes & 15 & & & 88 \\
\hline No & 2 & & & 12 \\
\hline \multicolumn{5}{|l|}{ Work-position } \\
\hline Worker/office worker & 11 & & & 65 \\
\hline Superior/team leader & 5 & & & 29 \\
\hline Cadres/manager & 1 & & & 6 \\
\hline
\end{tabular}

$N R S$ numeric rating scale, min. 0-max. 10

$N S L B P$ nonspecific low back pain

potential influence of this specific knowledge on the research questions. After 17 interviews no new themes emerged and, therefore, saturation was reached [29, 32]. Several themes emerged following the thematic analysis of the transcribed interviews. A total of eight themes of postures were mentioned: prolonged sitting, standing, walking, forward standing, crouching, forward sitting, bending, and whole body vibration (see Table 3). Examples of these themes are:

1. theme of prolonged sitting: (quotation) "Long sitting during driving a car, for example".

2. theme of prolonged standing: (quotation) "Standing calm, queuing, somewhere".

3. theme of prolonged walking: (quotation) "During walking ...".

4. theme of prolonged forward standing: (quotation) "Bent forward". 
5. theme of prolonged crouching: (quotation) "Kneeling or cowering for a prolonged time".

6. theme of prolonged forward sitting: (quotation) "... if I am sitting ... like in a forward bent position".

7. theme of prolonged bending: (quotation) "Bending over something ...".

8. theme of whole body vibration: (quotation) "During sledging, bus driving".

\section{Second Qualitative Analysis}

During the interviews participants reported that five out of the 17 items-i.e., lift 10 pounds from floor (item 10), unload 20 pounds (item 13), lift a 20-pound tool box from floor (item 16), get out of an automobile (item 32) and sweep with a broom (item 40)—were redundant. Hence, these five items were excluded to further reduce the number of items.

\section{M2: Quantitative Analysis of Previous SFS Data}

\section{Participants}

A total of 565 patients were previously investigated [17, $21,28]$. The proportion of males was $54 \%$, mean age was 43 years, and mean duration of LBP was 1154 days. All demographic characteristics are shown in Table 4.

\section{Internal Consistency}

Item-to-total analysis for all items showed a value of $>0.6$. Cronbach's alpha value for all items was 0.98 . When half of the items-one group with even and one group with odd numbered items-were analyzed, Cronbach's alpha value for both groups was 0.96. Four items (items 45-48) asking about heavy material handling tasks with $50 \mathrm{~kg}$ had itemto-total correlation values of $<0.40$ (item 45 : 0.36 , item 46 : 0.39, item 47: 0.33, item 48: 0.36).

\section{Unidimensionality}

The principal component analysis (PCA) revealed six components with eigenvalues exceeding 1 . Items 45, 47, and 48 all loaded with high values over 0.9 on the second, and item 46 on the fourth factor. Six items loaded on any factor of the six components, that is, items 4 (pushing and pulling), 22 (crouching), 33 (carrying $5 \mathrm{~kg}$ ), 34 (carrying $15 \mathrm{~kg}$ ), 37 (climbing a ladder), and 38 (climbing a ladder with $10 \mathrm{~kg}$ ).

\section{Item Response}

The infit and outfit mean square fit values from the Rasch analysis were consistently between 0.5 and 1.5 for all items, except for items 45-48, with values of $>2.0$.

\section{Floor and Ceiling Effect}

Four items (45-48), that is, tasks with lifting $50 \mathrm{~kg}$, showed a floor effect of $>85 \%$ of the included subjects.

\section{M3: Experts' Opinions}

Eight out of the 50 SFS items were consistently rated by all experts as important in relation to patients with chronic NSLBP (item 8: lower $5 \mathrm{~kg}$ from a bench to a floor, item 11: lifting $10 \mathrm{~kg}$ into trunk of an automobile, item 16: lifting $10 \mathrm{~kg}$ from the floor to a bench, item 19: wash dishes at a sink, item 27: load or unload dishwasher, item 34: carrying $15 \mathrm{~kg}$ over $15 \mathrm{~m}$, item 35: carrying $10 \mathrm{~kg}$ over $30 \mathrm{~m}$, and item 44: lifting $25 \mathrm{~kg}$ from the floor to a bench).

\section{Final Item Selection: Scoring}

For M-SFS, eight new prolonged body postures, which were claimed by the interviewed participants to cause LBP, were chosen from the 17 semi-structured interviews. Of the existing 50 items, 17 scored more than 9 points and were selected based on six criteria from the mixed methods approach consisting of M1, 2, and 3. After the second qualitative analysis, 12 items remained for the M-SFS. Six of these 12 items (items 8, 9, 11, 12, 15, and 50) in the new questionnaire describe tasks of lifting weights from 2.5 to $15 \mathrm{~kg}$. Activities where the spine is in a forward bent position are depicted in two items (items 3 and 19). Carrying weights of $10 \mathrm{~kg}$ over a distance of $30 \mathrm{~m}$ is represented in one item (item 36). One item requires rotation and lateral flexion of the spine (item 30). Repetitive bending and rising of the trunk with very low weight is referred to in one item (item 27) and another asks for lifting of $25 \mathrm{~kg}$ (item 44). This results in 20 items represented in the M-SFS (see "Appendix").

\section{Discussion}

A modified version of the SFS was achieved using a mixed methods approach resulting in a total of 20 items [39]. Semi-structured interviews with patients with chronic NSLBP revealed eight prolonged postures or movements that were associated with their LBP. These are: sitting, standing, walking, forward standing, crouching, forward sitting, whole body vibration, and repetitive bending. From the original 50 items of the SFS, 12 remained after item selection according to the adapted Stanton criteria for length reduction of self-reporting scales [38]. All items depicting lifting tasks with weights over $25 \mathrm{~kg}$ (items 45-48) were excluded from the M-SFS by the applied scoring system. This is in line with the current European 


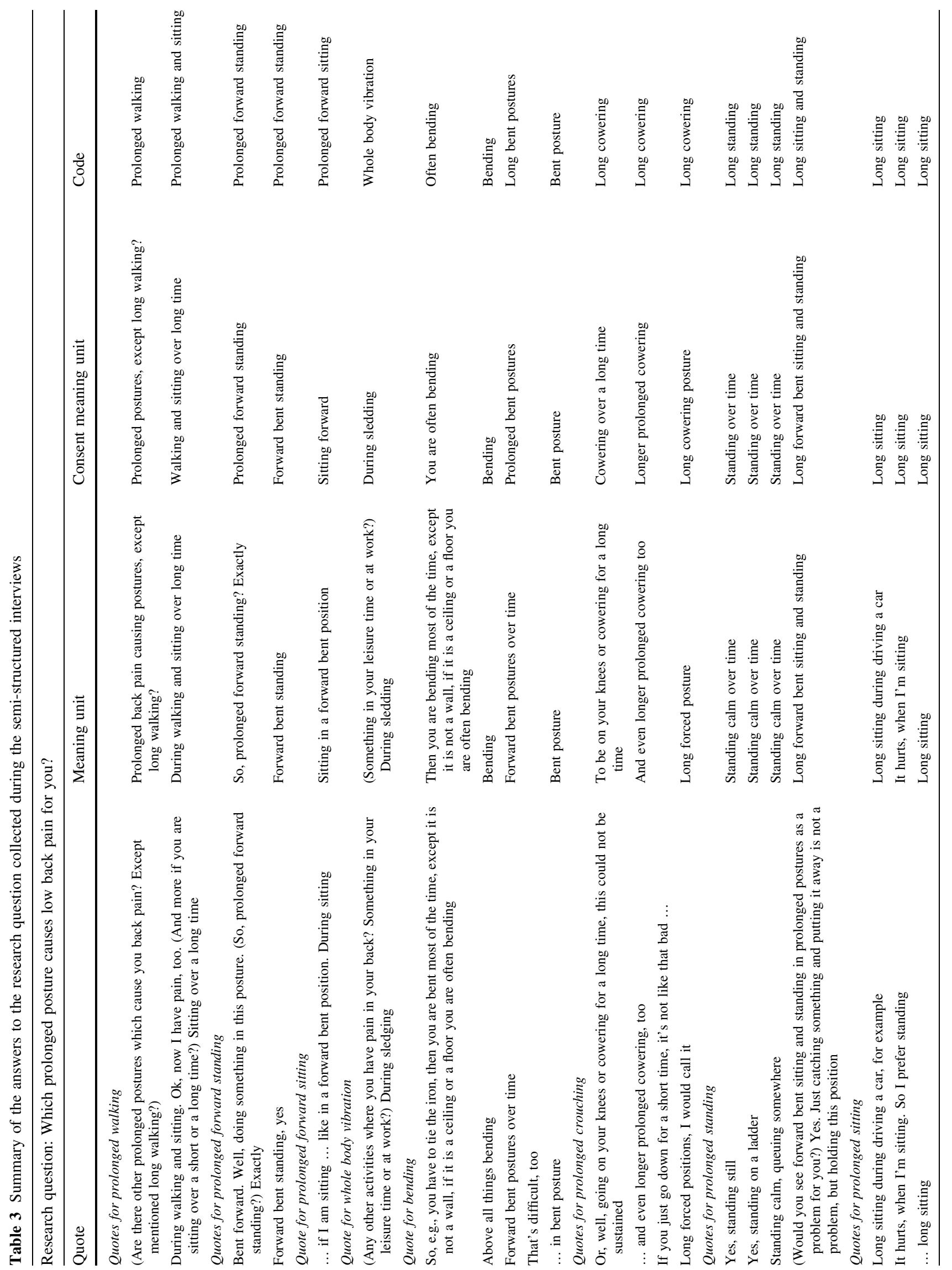




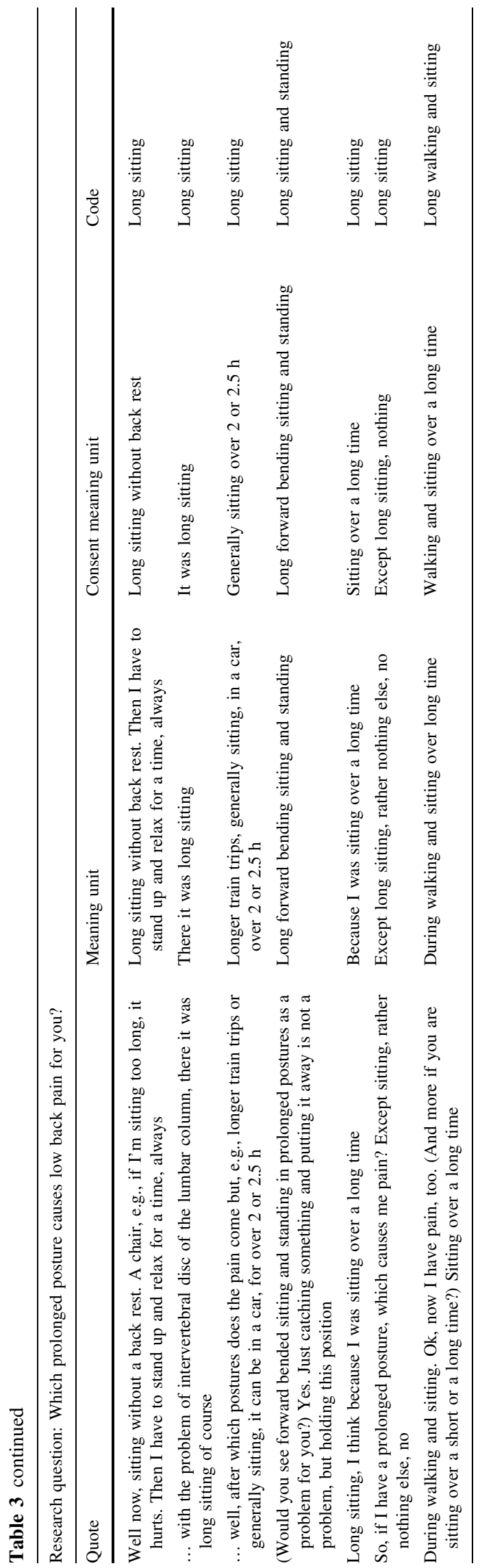

work safety guidelines which no longer recommend lifting tasks with weights over $25 \mathrm{~kg}$ [18].

The most relevant findings from the quantitative analysis of 565 SFS's obtained in previous studies [17, 21, 28] were the high Cronbach's alpha values of 0.98 of all items, and 0.96 if the sample was split into two groups-one group with even and one group with odd numbered items; six items loaded on any of the with PCA identified six components of the SFS; mean square fit values from the Rasch analysis between 0.5 and 1.5 for all items except for items $45-48$ with values $>2.0$; and large floor effects of four items depicting lifting tasks of $50 \mathrm{~kg}$ (items 45-48). These findings strongly support item reduction and modification of the SFS, as suggested in previous studies [17, $18,40]$.

The strength of this study is the mixed methods approach which combined interviews with subjects with CLBP, a quantitative analysis of the SFS items based on a high number of datasets obtained in previous studies [17, 21, 28], and experts' opinions. The findings from these methods were used within the final scoring system as recommended by Stanton et al. [38] for item reduction of self-reporting scales. An arbitrary cut-off value of 9 points was determined for this study. An item could have reached a maximal 12 points in the scoring, so it was supposed that an absolute majority over $75 \%$ of the maximum score would be adequate for a cut-off value. A further strength is the use of semi-structured interviews that allowed for new items of LBP-causing postures to be explored.

A weakness of this study is the small number of experts. Only four experts rated the relevance of the SFS items using a dichotomous questionnaire. Furthermore, the sample of participants included in the quantitative and qualitative analysis consisted of patients with chronic NSLBP. Therefore, the findings of this study may not be appropriate for patients with acute LBP or patients with other disorders.

It might also be argued that the M-SFS is lacking the internal validity check that was previously used. This aimed at identifying inconsistencies in answers and was achieved by including two identical items. However, we performed a post hoc analysis with the 565 SFS's obtained in previous studies revealing that inconsistencies between these identical items were extremely rare. We therefore feel that such a check is redundant. However, further research must be performed to clarify whether the internal validity check is indeed redundant. Further research must also investigate the feasibility, test-retest reliability, and construct validity of the M-SFS. A study with patients with chronic NSLBP is planned to investigate these measurement properties. 
Table 4 Demographic characteristics of patients with chronic $\operatorname{NSLBP}(\mathrm{n}=565)$

\begin{tabular}{|c|c|c|c|c|}
\hline Variable & $\mathrm{n}$ & Mean & SD & $\%$ \\
\hline Age & 565 & 43 & 10.2 & \\
\hline Self-reported pain (NRS) & 561 & 5 & 1.8 & \\
\hline Duration of pain (days) & 541 & 1154 & 2011.8 & \\
\hline \multicolumn{5}{|l|}{ Gender } \\
\hline Male & 303 & & & 54 \\
\hline Female & 262 & & & 46 \\
\hline \multicolumn{5}{|l|}{ Education (years at school) } \\
\hline 6 years & 256 & & & 46 \\
\hline $7-9$ years & 276 & & & 50 \\
\hline$>9$ years & 25 & & & 4 \\
\hline \multicolumn{5}{|l|}{ Marital status } \\
\hline Single & 111 & & & 20 \\
\hline Married & 173 & & & 66 \\
\hline Divorced/parted & 75 & & & 13 \\
\hline Unknown & 5 & & & 1 \\
\hline \multicolumn{5}{|l|}{ Native language } \\
\hline (Swiss) German & 307 & & & 54 \\
\hline French & 7 & & & 1 \\
\hline Italian & 21 & & & 4 \\
\hline Spanish & 37 & & & 6 \\
\hline Portuguese & 14 & & & 2 \\
\hline Serbo-Croatian & 90 & & & 16 \\
\hline Albanian & 20 & & & 3 \\
\hline Turkish & 15 & & & 3 \\
\hline Other $^{\mathrm{a}}$ & 54 & & & 10 \\
\hline \multicolumn{5}{|l|}{ Work-contract } \\
\hline Yes & 274 & & & 49 \\
\hline Do not know & 89 & & & 16 \\
\hline No & 181 & & & 32 \\
\hline Other $^{b}$ & 14 & & & 2 \\
\hline \multicolumn{5}{|l|}{ Work-position } \\
\hline Unskilled worker/trainee & 182 & & & 32 \\
\hline Worker/office worker & 325 & & & 57 \\
\hline Superior/team leader & 24 & & & 4 \\
\hline Cadres/manager & 6 & & & 1 \\
\hline Owner/self-employed & 24 & & & 4 \\
\hline Unknown & 3 & & & 0.5 \\
\hline
\end{tabular}

NRS numeric rating scale min. $0-\max .10$

a Native language: other (English, Croatian, Macedonian, Slovenian, Bosnian)

b Work status: other (non-retired, temporary employment, uncertain)

\section{Conclusion}

Based on the results of a mixed methods approach, a modified SFS requiring less administration time was developed. This consists of 12 items from the existing SFS and eight new items that include patient's beliefs about back pain causing postures and movements. Feasibility, reliability, and validity of the M-SFS need to be explored in future studies before it can be used in clinical practice.

Acknowledgments The authors thank Peter Erhart for providing data from the Outcome study. We also thank Olivia Teruggia for assistance with the interview transcription and Axel Gehrke for data preparation and technical support. We also thank all the subjects for their participation.

Author contributions S.J. and M.A.T. were responsible for funding and conducting the study at the Rehaklinik Bellikon and P.O. for conducting the study at the Rehabilitation Centre Valens. S.J., M.A.T., and R.H. performed the statistical analysis. S.J. drafted the first version of the manuscript. S.J., M.A.T., R.H. and P.O. were involved in the design, the method, and the interpretation of the results, and read and approved the final version of the manuscript study report.

\section{Compliance with ethical standards}

Conflict of interest This study was funded in part by a Grant from the Swiss Accident Insurance Fund (SUVA). However, no funding bodies had any role in the study design, data collection and analysis, decision to publish, or preparation of the manuscript. All authors declare that they have no conflict of interest.

Ethical standard All procedures followed were in accordance with the ethical standards of the responsible committees on human experimentation (institutional and national) and with the Helsinki Declaration of 1975, as modified in 2000. Informed consent was obtained from all participants included in the study.

Open Access This article is distributed under the terms of the Creative Commons Attribution 4.0 International License (http://crea tivecommons.org/licenses/by/4.0/), which permits unrestricted use, distribution, and reproduction in any medium, provided you give appropriate credit to the original author(s) and the source, provide a link to the Creative Commons license, and indicate if changes were made.

\section{Appendix}

See Table 5. 
Table 5 Modified spinal function sort (M-SFS)

\begin{tabular}{|c|c|c|c|c|c|c|}
\hline \multirow[b]{2}{*}{1} & \multirow[b]{2}{*}{ Place or retrieve a $2.5 \mathrm{~kg}$ can between waist and overhead } & \multirow{2}{*}{$\frac{\text { Able }}{1}$} & \multicolumn{3}{|c|}{ Restricted } & \multirow{2}{*}{$\frac{\text { Unable }}{5}$} \\
\hline & & & 2 & 3 & 4 & \\
\hline 2 & Lower a 10 pound milk crate from a bench to the floor & 1 & 2 & 3 & 4 & 5 \\
\hline 3 & Lift a $5 \mathrm{~kg}$ milk crate from the floor to eye level & 1 & 2 & 3 & 4 & 5 \\
\hline 4 & Load a $10 \mathrm{~kg}$ grocery bag into the trunk of an automobile & 1 & 2 & 3 & 4 & 5 \\
\hline 5 & Lower a $10 \mathrm{~kg}$ milk crate from eye level to the floor & 1 & 2 & 3 & 4 & 5 \\
\hline 6 & Unload two $5 \mathrm{~kg}$ grocery bags from the trunk of an automobile & 1 & 2 & 3 & 4 & 5 \\
\hline 7 & Carry two $5 \mathrm{~kg}$ sacks of groceries for $30 \mathrm{~m}$ & 1 & 2 & 3 & 4 & 5 \\
\hline 8 & Lift a $25 \mathrm{~kg}$ tool box from the floor to a bench & 1 & 2 & 3 & 4 & 5 \\
\hline 9 & Wash dishes at a sink & 1 & 2 & 3 & 4 & 5 \\
\hline 10 & Load or unload a dishwasher & 1 & 2 & 3 & 4 & 5 \\
\hline 11 & Push and pull a vacuum cleaner & 1 & 2 & 3 & 4 & 5 \\
\hline 12 & Get into an automobile driver's seat & 1 & 2 & 3 & 4 & 5 \\
\hline 13 & Stand for a prolonged time & 1 & 2 & 3 & 4 & 5 \\
\hline 14 & Walk for a prolonged time & 1 & 2 & 3 & 4 & 5 \\
\hline 15 & Stand bent forward over for a prolonged time & 1 & 2 & 3 & 4 & 5 \\
\hline 16 & Crouch for a prolonged time & 1 & 2 & 3 & 4 & 5 \\
\hline 17 & Sit bent forward for a prolonged time & 1 & 2 & 3 & 4 & 5 \\
\hline 18 & Bend forward repeatedly & 1 & 2 & 3 & 4 & 5 \\
\hline 19 & Sit on a chair for a prolonged time & 1 & 2 & 3 & 4 & 5 \\
\hline 20 & Sit with whole body vibration for a prolonged time; e.g. a bus journey & 1 & 2 & 3 & 4 & 5 \\
\hline
\end{tabular}

\section{References}

1. McLean SM, May S, Klaber-Moffett J, Sharp DM, Gardiner E. Risk factors for the onset of non-specific neck pain: a systematic review. J Epidemiol Community Health. 2010;64(7):565-72. doi:10.1136/jech.2009.090720.

2. Jeffries LJ, Milanese SF, Grimmer-Somers KA. Epidemiology of adolescent spinal pain: a systematic overview of the research literature. Spine. 2007;32(23):2630-7. doi:10.1097/BRS.0b013e 318158d70b.

3. Hoy D, Bain C, Williams G, March L, Brooks P, Blyth F, et al. A systematic review of the global prevalence of low back pain. Arthritis Rheum. 2012;64(6):2028-37. doi:10.1002/art.34347.

4. Balagué F, Mannion AF, Pellisé F, Cedraschi C. Non-specific low back pain. Lancet. 2012;379(9814):482-91.

5. van Tulder M, Becker A, Bekkering T, Breen A, Gil del Real MT, Hutchinson A, et al. Chapter 3. European guidelines for the management of acute nonspecific low back pain in primary care. Eur Spine J. 2006;15(Suppl 2):S169-91. doi:10.1007/s00586006-1071-2.

6. Rahman A, Reed E, Underwood M, Shipley M, Omar R. Factors affecting self-efficacy and pain intensity in patients with chronic musculoskeletal pain seen in a specialist rheumatology pain clinic. Rheumatology. 2008;47(12):1803-8.

7. Self-efficacy Bandura A. In: Ramachaudran V, editor. Encyclopedia of human behavior. New York: Academic Press; 1994. p. 71-88.

8. Rahman A, Reed E, Underwood M, Shipley M, Omar R. Factors affecting self-efficacy and pain intensity in patients with chronic musculoskeletal pain seen in a specialist rheumatology pain clinic. Rheumatology. 2008;47(12):1803-8.

9. Holden G. The relationship of self-efficacy appraisals to subsequent health related outcomes: a meta-analysis. Soc Work Health Care. 1991;16(1):53.

10. Engel GL. The need for a new medical model: a challenge for biomedicine. Science. 1977;196(4286):129-36.
11. Bandura A. Self-efficacy: toward a unifying theory of behavioral change. Psychol Rev. 1977;84(2):191-215.

12. van Abbema R, Lakke SE, Reneman MF, van der Schans CP, van Haastert CJ, Geertzen JH, et al. Factors associated with functional capacity test results in patients with non-specific chronic low back pain: a systematic review. J Occup Rehabil. 2011;21(4):455-73.

13. Burrus C, Ballabeni P, Deriaz O, Gobelet C, Luthi F. Predictors of nonresponse in a questionnaire-based outcome study of vocational rehabilitation patients. Arch Phys Med Rehabil. 2009;90(9):1499.

14. Mooney V, Matheson LN, Verna J, Leggett S, Dreisinger TE, Mayer JM. Performance-integrated self-report measurement of physical ability. Spine J. 2010;10(5):433-40.

15. Matheson LN, Matheson ML, Grant J. Development of a measure of perceived functional ability. J Occup Rehabil. 1993;3:15-30.

16. Gibson L, Strong J. The reliability and validity of a measure of perceived functional capacity for work in chronic back pain. J Occup Rehabil. 1996;6(3):159-75.

17. Oesch PR, Hilfiker R, Kool JP, Bachmann S, Hagen KB. Perceived functional ability assessed with the spinal function sort: is it valid for European rehabilitation settings in patients with nonspecific non-acute low back pain? Eur Spine J. 2010;19(9): 1527-33. doi:10.1007/s00586-010-1429-3.

18. Borloz S, Trippolini MA, Ballabeni P, Luthi F, Deriaz O. Crosscultural adaptation, reliability, internal consistency and validation of the spinal function sort (SFS) for French- and Germanspeaking patients with back complaints. J Occup Rehabil. 2012;22(3):387-93. doi:10.1007/s10926-012-9356-2.

19. Mayer J, Mooney V, Matheson L, Leggett S, Verna J, Balourdas $\mathrm{G}$, et al. Reliability and validity of a new computer-administered pictorial activity and task sort. J Occup Rehabil. 2005;15(2): 203-13.

20. Oliveri M, Jansen T, Oesch P, Kool J. The prognostic value of functional capacity evaluation in patients with chronic low back pain: part 1: timely return to work. And part 2: sustained recovery. Spine. 2005;30(10):1232-3; author reply 3-4. 
21. Kool JP, Oesch PR, Bachmann S, Knuesel O, Dierkes JG, Russo $\mathrm{M}$, et al. Increasing days at work using function-centered rehabilitation in nonacute nonspecific low back pain: a randomized controlled trial. Arch Phys Med Rehabil. 2005;86(5):857-64. doi:10.1016/j.apmr.2004.10.044.

22. Matheson L, Matheson M, Grant J. Development of a measure of perceived functional ability. J Occup Rehabil. 1993;3(1):15-30. doi:10.1007/bf01076739.

23. Matheson LN., Matheson ML. Spinal function sort. Rating of perceived capacity. Test booklet and examiners manual. Performance Assessment and Capacity Testing PACT1989/1991.

24. Fayad F, Lefevre-Colau MM, Poiraudeau S, Fermanian J, Rannou $\mathrm{F}$, Wlodyka Demaille $\mathrm{S}$, et al. Chronicité, récidive et reprise du travail dans la lombalgie: facteurs communs de pronostic [Chronicity, recurrence, and return to work in low back pain: common prognostic factors]. Annales de Readaptation et de Medecine Physique. 2004;47(4):179-89. doi:10.1016/j.annrmp. 2004.01.005.

25. De Beeck RO, Hermans V. Research on work-related low back disorders. Brussels: Institute for Occupational Safety and Health; 2000.

26. Creswell JW, Plano Clark VL. Designing and conducting mixed methods research. 2nd ed. Los Angeles: SAGE; 2011.

27. Plano Clark VL, Creswell JW. The mixed method reader. Los Angeles: SAGE; 2008.

28. Iakova M, Ballabeni P, Erhart P, Seichert N, Luthi F, Deriaz O. Self perceptions as predictors for return to work 2 years after rehabilitation in orthopedic trauma inpatients. J Occup Rehabil. 2012;22(4):532-40.

29. Flick U, Von Kadrorff E, Steinke I, editors. Qualitative Forschung. Ein Handbuch. 8th ed. Hamburg: Rowolt Taschenbuch Verlag; 2010.

30. Pool J. Neck pain: "a pain in the neck?": a study of therapeutic modalities and clinimetrics. Enschede: Gildeprint Drukkerijen B.V; 2007.
31. Graneheim UH, Lundman B. Qualitative content analysis in nursing research: concepts, procedures and measures to achieve trustworthiness. Nurse Educ Today. 2004;24(2):105-12. doi:10. 1016/j.nedt.2003.10.001.

32. de Vries HJ, Brouwer S, Groothoff JW, Geertzen JH, Reneman MF. Staying at work with chronic nonspecific musculoskeletal pain: a qualitative study of workers' experiences. BMC Musculoskelet Disord. 2011;12:126. doi:10.1186/1471-2474-12-126.

33. Portney LG, Watkins MP. Reliability foundations of clinical research. Applications to practice. Upper Saddle River: PrenticeHall Health; 2000. p. 67.

34. R Development Core Team. R: a language and environment for statistical computing. Vienna: R Foundation for Statistical Computing; 2011.

35. Winsteps 3.8, Chicago, IL, USA

36. Linacre JM. What do infit and outfit, mean-square and standardized mean. Rasch Meas Trans. 2002;16(2):878.

37. Streiner DL. Figuring out factors: the use and misuse of factor analysis. Can J Psychiatry. 1994;39(3):135-40.

38. Stanton JM, Sinar EF, Balzer WK, Smith PC. Issues and strategies for reducing the length of self-report scales. Pers Psychol. 2002;55(1):167-94.

39. Campbell P, Wynne-Jones G, Muller S, Dunn KM. The influence of employment social support for risk and prognosis in nonspecific back pain: a systematic review and critical synthesis. Int Arch Occup Environ Health. 2013;86(2):119-37. doi:10.1007/ s00420-012-0804-2.

40. Trippolini MA, Dijkstra PU, Geertzen JH, Reneman MF. Measurement properties of the spinal function sort in patients with sub-acute whiplash-associated disorders. J Occup Rehabil. 2015;25(3):527-536. 